\title{
Diversity Awareness for Assisting Intercultural Teaching and Learning
}

\author{
Jiuai Sun, Yiwen Tang, Zhonghang Wu \\ School of Medical Imaging \\ Shanghai University of Medicine and Health Sciences \\ Shanghai, China \\ E-mail: sunja, Tangyw,Wuzh@sumhs.edu.cn
}

\begin{abstract}
As China economy grows dramatically in recent years, more and more students from the other part of the world come to study in China. However the Chinese teaching and learning styles has been found much different from those western countries. Therefore it is necessary to make sure that both teaching staff and foreign learners become aware how much difference exists so that they can make themselves adapt to the new circumstance. This paper first reviews the different teaching and learning style between Eastern and Western, then attempt to seek the reasons to cause this variation. In the last several suggestions are provided as learning strategies for those involving either multicultural teaching or learning activities.
\end{abstract}

Keywords: teaching and learning; style; cultrue

\section{INTRODUCTION}

Our globalization era demands a great amount of international workforce and the China is becoming one of the best places to study or train because of her fast economic development advantages and fascinating difference from the other part of world. According to China's Ministry of Education (MOE), the total share of international students seeking higher-education degrees in China grew by 13 percent over the past 10 years, jumping from almost 55,000 students in 2006 to nearly 210,000 students in 2016. China attracts more international students than any other Asian power and ranks third globally, only behind the United States and the United Kingdom [1].

Teaching groups of foreign students or studying in a country different from the one you grew up are considered challenging by people. Lots of cases have witnessed and impressed by distinctive difference of western and eastern education systems. Without knowing and utilizing such difference may cause failure or frustration during teaching and learning. Research has shown that the teaching and learning styles used in one country cannot be directly transferred to design management courses in others [2]. Thus, many foreign students face difficulties in adapting themselves to unfamiliar education systems. This situation may lead to poor experiences where teaching and learning activities are not designed with foreign students in mind.

This paper intends to identify the difference from authors' partially understandings (mainly using China and UK/US as examples) and explore the cause of this difference, in order to inform strategies for the accommodation of multinational cohorts and indicate what we can learn for assisting or enhancing our teaching and learning practices.

\section{EASTERN AND WESTERN LEARNING AND TEACHING STYLES}

Various studies have investigated the characteristics of Chinese learning style across a range of period [3, 4]. In general Majority of China's teaching and learning is still regarded as a teacher-centered, book-centered method with an emphasis on rote memory. This probably follows the traditional Chinese Imperial examination system whose purpose was[5]:

"the creation of bureaucratic generalists familiar with an accepted ethical outlook and body of knowledge, not with the growth of knowledge or with academic specialization"

This training system results in a number of unique teaching and learning styles which are contrastingly different from those western styles as summarized and compared in the following table $[6,7,8]$.

\section{Eastern}

- Depend and follow on the teacher

- Passive learners

- Achievement of the group

- Respect for historical texts books

- 'Surface' or rote learners

- Closure \& detailedoriented style

\section{Western}

- Critical thinking and learning

- Argumentative learners

- Achievement of the individual

- Constructing new knowledge

- 'Deep' learners seeking

- Open discussion
Without knowing these different characteristics, some confusion or difficulties may be easily triggered for eastern teachers to teach western students and vice versa. One typical phenomenon is worth to mentioning here: eastern students normally show little response to the questions in the lecture, but queue for seeking clarification after the lecture. It may be considered to utilize the time unwisely in the western culture, but it is rather common in the eastern, where the teachers are dominating and authoritative in the class and at a higher level in the social hierarchy. So you may expect less 
question raised in the classroom or no opportunities to make your response to the question during lecturing. Practically two-way communication is hardly found to exchange ideas in the classroom. Another reason for this inactive attitude may be explained as fearing of embarrassing the lecturer by questioning, or unwilling to lose face by asking a probably simple or 'stupid' question [9].

\section{THE UNDERLYING REASONS}

Although individual learning style always differs from each other because of learning experience, personality and context, most of ancient Chinese students demonstrate the common features mentioned above. This may be traced back to their cultural, where their beliefs, languages and traditions are developed.

Actually before school begins, Chinese shows much different in learning even as early as at their infant days. Whereas Chinese parents use illustration and gentle guidance, a learning style known as teaching by hand-holding, their Western counterparts emphasize self-reliance, creative solutions and problem-solving skills. Thus, the Chinese education at the earliest stages stresses the mastery of technical skill, learning through mimicry, concentrated discipline - and the value of respectful conformity. In contrast, Western education tends to value free experimentation, creativity and original expression.

To explain this phenomenal we may trace back to their cultural, on which their beliefs, languages and traditions are developed. Most East Asia countries are strongly influenced by Confucianism, a most important ethical and philosophical system developed by Confucius more than two thousand years ago[10]. Confucius emphasized the importance of education and developed a tradition of a ruthlessly competitive education and selection process to train people to memorize a vast amount of classical Confucianism material. This may be where the origin of rote learning style came from.

The teaching and learning style may present efficiency for those disciplines requiring structure knowledge such as language, laws and management, but may not be excellent for those reasoning and computational disciplines like mathematic physics and engineering. As a matter of fact it did help the old empires to govern and stabilize for a relative long period, but obviously the growth of nature science was constrained.

Jin suggested that at the core of the East Asian learner is the aim of "transforming oneself," consistent with Confucian principles, whereas at the core of the Western learner is the aim of "learning to master the universe," consistent with Socratic principles. i.e. cultivating the self to become perfected morally and socially (i.e., the virtue model) in the East Asian tradition places the emphasis on one's internal world, the whole person, and perfecting the person, namely, one's authenticity and one's integrity. In contrast, cultivating the mind to understand and master the world (i.e., mind model) in the Western tradition places the emphasis on the external world, the mind and critical thinking, knowledge of the world, and the products and things in the universe represented by the sciences. Therefore Western learning has led to the creation of scientific knowledge and products that have been used to eliminate disease, improve health, reduce hunger, and provide shelter worldwide. On the other hand, East Asian learning has led to China's decline; its rude awakening to its decline after the Cultural Revolution resulted in the rejection of Confucianism, seen to be the root cause. Confucianism was the philosophic foundation of society for thousands of years, prescribing the rules of engagement for the ruling classes prior to communism.

This difference between the East and the West are thus based on profound cultural differences that will be glacially slow to shift. However a global educational environment is emerging which offers an ever-widening variety of choice for both Chinese and Western countries, more and more Chinese parents are sending their children to go to Western countries for their primary education and higher education and students around the world enroll Chinese schools to study, as mentioned in the early context. Whatever it is the Chinese students filling the classrooms or a Western schoolboy learning to speak Mandarin and attending a local Chinese school, it is essential to be aware cultural variation in order to communicate and exchange idea effectively.

\section{STRATEGIES TO OVERCOME THE LEARNING DIVERSE}

By looking at the latest successful results in the Program for International Student Assessment (PISA) education where East Asian countries have ranked the highest in test, there must be many positive approaches we may keep on or learn for assisting us to facilitate the learning and teaching experience.

There are much more dependence on course books in the eastern learning and teaching system. Most Asian students expect their lecturers to point out which course books they should read and even which parts they should exactly put more emphasis during study so to earn better grade. While this may be regarded by western students as time-demanding request for lecturers, it is actually completely natural here. Therefore by understanding of this difference it's wise for foreign learners to allocate more time on the context indicated by the lecturers rather than broaden own interests without any limits. Teachers could approach those students from outside and build a closer and more trusting relationship in order to guarantee the students are on your track.

Collective learning is especially useful in helping group students to develop social and team working skills as they are provided a good platform to interact with new peers, to obtain mutual support and develop higher level of friendship and trust during collaboration. It also offers good opportunity for people to experience diverse cultures and adapt themselves as soon as possible. Researches have shown that students are easier to make good achievement in groups where they tend to exchange of ideas and information or 
make contribution for a team [11]. In order to successfully develop a good collaborative learning program, it is key factor for the teachers to make a good preparation including develop the context for the collective project, allocating right figurers for a team and work as facilitator to move the team forward et.al.

A number of new teaching and learning strategies are suggested and verified in recent years. Among them the flip classroom strategy is successful one[12]. Rather than purely rely on the students to present and explain the lecture content assigned in the early lecture, we may ask students to cover part of the content at first stages and gradually learn to deliver full lecture. This approach will be easier to work on those mature students and enable a shift towards studentcentric learning style.

\section{CONCLUSION-BRIDGE THE DIFFERENCE}

It should be mutual responsibility to recognize and understand the culture diversity when we want to ensure effective teaching and learning outcomes. Every learning and teaching style have their characteristics. The students who enter into a different country should make them ready to change their own learning style. On the other hand, as dedicated teachers or senior counterparts, we should know more about the learners' learning styles so more appropriate material and strategies can be created to accommodate the learning styles from different culture background.

The diversity of learners' background and experience present us a challenge, but we may enhance our teaching and learning capability by developing suitable pedagogical theory and skills to support a learning process. The following is not systematically model, but rather a summary of practical strategies which may be used to bridge a Western teacher to the needs of their East Asia (Chinese) students in a quick way [13, 14]:

- Diversify teaching styles to take multiple learning styles into consideration

- Help new learners aware the merit of and involve into the communicative and collective learning approach at early stage of courses

- Provide a systematic and detail plan of the course to enhance mutual understanding

- Choose those topics work within the scope of common cultural background for the group

- Control the delivery rate of speech and context, with frequent feedback checks from learners

- Stimulate the new learner's enthusiasm by using video and film media towards a communicative approach
- Build a good relationship between students and teacher may work more effective than any other strategies above

\section{ACKNOWLEDGMENT}

This study was supported by the educational and teaching reform project of shanghai university of medicine \& health sciences (JG (18)06-A2-01). The authors warmly thank to the anonymous reviewers whose suggestions and questions helped the authors improve the paper.

\section{REFERENCES}

[1] https://chinapower.csis.org/china-international-students/

[2] Williams A. J. and Guo F. B., (2006), A comparative study of design education across higher education institutions within China and the UK, in Proceedings of D2B: The First International Design Management Symposium, Shanghai

[3] Sit Helena, Hing Wa, (2013), Characteristics of Chinese students' learning styles, International proceedings of economics development and research, Vol. 62, p.36-39;

[4] Dunn, R. (1990). Understanding the Dunn and Dunn Learning Styles Model and the Need for Individual Diagnosis and Prescription. Reading, Writing and Learning Disabilities, 6, 223 - 247.

[5] Merson J (1990) The Genius that was China: East and West in the making of the modern world, Overlook Press

[6] Wong J (2004) Are the learning styles of Asian International students culturally or contextually based? International Education Journal, 4 (4), pp 154-166

[7] Littrell, R F. (2006) Learning styles of students in and from Confucian cultures. In Ong Siow Heng, Gerhard Apfelthaler, Katrin Hansen, Nirundon Tapachai, eds. Intercultural Communication Competencies in Higher Education and Management, Singapore: Marshall Cavendish Academic.

[8] Tian J, Low G (2011) Critical thinking and Chinese university students: a review of the evidence, Language, Culture and Curriculum, 24(1), pp 61-76

[9] Bond K, Scudamore R (2010) Working with international students: a guide for staff in Engineering, higher education academy Engineering subject centre. ISBN 978-1-907632-10-5

[10] Yum J O, (1994) The impact of Confucianism on interpersonal relationships and communication patterns in East Asia. In L. A. Samovar \& R. E. Porter (Eds.), Intercultural communication: A reader pp. 75-86. Belmont, CA: Wadsworth

[11] Kurucay, M. and Inan, F.A. (2017), Examining the effects of learnerlearner interactions on satisfaction and learning in an online undergraduate course, Computers \& Education, Vol. 115, pp. 20-35.

[12] Ahmad, Nasir. (2015). Effects of Flip Learning Approach on Prospective Teachers' Pedagogical Skills. The Dialogue. 10. 326-337.

[13] Jin Li, (2013). Cultural Foundations of Learning: East and West. Politics, Culture and Socialization. 4. 94-97.

[14] Xiao L (2004) Bridging the gap between teaching styles and learning styles: A cross-cultural perspective, Teaching English as a Second or Foreign Language, 10 (3), pp 1-15 